\title{
A Retrospective Cross-Sectional Analyses of Swallowing and Tongue Functions in Maxillectomy Patients
}

Yoichiro Ogino ( $\sim$ ogino@dent.kyushu-u.ac.jp )

Kyushu University https://orcid.org/0000-0002-4807-8224

\section{Natsue Fujikawa}

Kyushu University

\section{Sayuri Koga}

Kyushu University

\section{Ryoji Moroi}

Kyushu University

\section{Kiyoshi Koyano}

Kyushu University

\section{Research Article}

Keywords: swallowing function, maxillectomy, tongue functions, cancer-related therapy

Posted Date: February 9th, 2021

DOI: https://doi.org/10.21203/rs.3.rs-159878/v1

License: (9) This work is licensed under a Creative Commons Attribution 4.0 International License. Read Full License

Version of Record: A version of this preprint was published at Supportive Care in Cancer on March 31st, 2021. See the published version at https://doi.org/10.1007/s00520-021-06186-w. 


\section{Abstract \\ Purpose}

To investigate the profiles of swallowing and tongue functions, and to identify factors influencing swallowing in maxillectomy patients.

\section{Methods}

Maxillectomy patients whose swallowing function defined by Eating Assessment Tool (EAT-10) score and tongue functions (oral diadochokinesis: ODK, maximum tongue pressure: MTP) with or without maxillofacial prostheses had been evaluated were enrolled in this study. The effects of the history of radiotherapy or soft palate resection on swallowing function were evaluated. The effect of radiotherapy on oral dryness was also evaluated. To examine correlations of swallowing function with continuous variables, Spearman correlation coefficients were calculated.

\section{Results}

A total of 47 maxillectomy patients (23 males and 24 females, median age:71 [IQR: 63-76]) were registered. The median value of EAT-10 scores was 3 [IQR: $0-14]$. Patients with the history of radiotherapy, but not with soft palate resection, showed significantly declined swallowing function. ODK and MTP of patients wearing maxillofacial prostheses were significantly improved. No significant effect of radiotherapy on oral dryness was found. A significant correlation was found between EAT-10 score and MTP $(P=0.04)$.

\section{Conclusions}

Swallowing function in maxillectomy patients was relatively impaired and the patients with the history of radiotherapy showed lower swallowing function. Maxillofacial prostheses could contribute to the improvement of MTP and ODK (/ta/). MTP may play a crucial role in swallowing in maxillectomy patients.

\section{Introduction}

Maxillectomy following head and neck, or oral cancers may cause maxillary defect and subsequent aesthetic and functional impairments, resulting in deterioration in quality of life (QoL) and oral healthrelated QoL (OHRQoL) [1-4]. It is definitely important to restore oral functions, including mastication and swallowing, with surgical and/or prosthetic (including an obturator or a maxillofacial prosthesis) rehabilitation after the resection. Aesthetic and functional outcomes of maxillectomy depend on intraand extra-oral conditions and the method of rehabilitation. Although primary closure is a predictable 
method for better oral functions, patients who got greater extent of resections generally need surgical reconstructions with grafts and/or rehabilitation with maxillofacial prostheses [4]. Furthermore, most of these patients also lose their teeth and need to replace the teeth with maxillofacial dentures to restore oral functions.

There have been so many reports that assessed masticatory function in maxillectomy patients subjectively and objectively. They demonstrated that several factors were related to masticatory function [5-10]. Compared to the patients without any maxillofacial defects, maxillectomy patients specifically have more factors that affect masticatory function, such as defect size and configuration [5, 7-9], and postoperative conditions of masticatory muscle, tongue and soft tissue [8-10] as well as remaining teeth $[5,9]$, occlusal supports [9], quality of prostheses [9] and occlusal force [6, 9, 10], which are also regarded as important factors in the patients without any maxillofacial defects.

Swallowing is equally important for well-nutrition, whereas it must be an extremely complex neuromuscular process $[11,12]$. In maxillectomy patients, swallowing is often impaired by resection and radiotherapy [13-16] and previous studies evaluated the effect of maxillofacial prostheses on swallowing after maxillectomy [16-22], although functional impacts of maxillofacial prostheses remain controversial because multiple variables are related to swallowing. However, it is obvious that tongue functions play a crucial role in swallowing, especially during oral and pharyngeal phase [23-26]. Contact of tongue against the hard palate or a prosthesis and tongue dynamics are representative assessment factors and it is reasonable to suppose that these are influenced by surgical and prosthetic interventions in maxillectomy patients.

The purpose of this study was to evaluate tongue functions and swallowing function in maxillectomy patients and to identify predictable factors for estimating swallowing function in maxillectomy patients. The null hypothesis in this study was that no factors were significantly correlated with swallowing function in maxillectomy patients.

\section{Materials And Methods}

This cross-sectional retrospective study was conducted in the Department of Prosthodontics, Kyushu University Hospital. The study protocol was approved by the ethics committee of Kyushu University, Faculty of Dental Science (2019-144). The investigation in the present study was carried out in compliance with Helsinki declaration and the Strengthening the Reporting of Observational Studies in Epidemiology (STROBE) guidelines.

\section{Study population}

Maxillectomy patients who had prosthetic rehabilitation from April, 2016 to January 2019 were included in this study. The inclusion criteria were as follows: 1) age: 20 years old or older, 2) the history of maxillectomy due to cancer and maxillofacial prosthetic rehabilitation with or without surgical reconstruction, 3) patients who had been evaluated their swallowing function and tongue functions. The 
exclusion criteria were as follows: 1) patients with ongoing cancer therapy such as chemotherapy and radiotherapy, 2) the history of additional head and neck cancers other than original cancer attributed to maxillectomy. The following patient profiles were extracted from patient charts: age, number of remaining teeth and, the history of radiotherapy and soft palate resection.

\section{Assessment of swallowing function}

Swallowing function was assessed using Eating Assessment Tool (EAT-10) score. This self-administered, symptom-specific outcome instrument has been utilized for diagnosis of dysphagia [27-29].

\section{Assessment of tongue functions}

In this study, tongue functions included tongue motor function and maximum tongue pressure. Tongue motor function was determined by oral diadochokinesis (ODK) $[28,29]$. Patients were asked to utter /ta/ repeatedly as quickly as possible for 5 seconds. This method is useful to assess the elevation of anterior region of the tongue, which is observed during initial swallowing. The number of the syllables uttered per second was determined using an automatic counter (Kenkokun Handy, Takei Scientific Instruments Co., Ltd., Niigata, Japan). Maximum tongue pressure (MTP) was recorded using a tongue pressure measuring instrument equipped with a balloon probe (JMS tongue pressure measuring instrument TPM-01, JMS Co., Ltd., Hiroshima, Japan) [26, 28]. Patients were instructed to compress the inflated balloon between tongue and anterior part of palate (including denture base) by elevating tongue. The measurements were conducted in triplicate and the average values were calculated. These functions were evaluated in patients with or without their maxillofacial prostheses.

\section{Assessment of oral dryness}

Saliva is known to form a bolus which is ready for swallowing, implying that saliva secretion can be a trigger of swallowing. Additionally, oral dryness, known as xerostomia, is one of the major radiationinduced side effects. In this study, oral dryness was also measured using an oral moisture checker (Mucus, Life Co., Ltd., Saitama, Japan) as a previous study showed [28].

\section{Statistical analyses}

The data including patient profiles (age and number of remaining teeth) were presented descriptively using medians with interquartile ranges (IQRs). For comparative analyses, data distribution was displayed in a box plot. The scores of EAT-10 and oral dryness in patients with or without the history of radiotherapy were compared using Wilcoxon rank sum test. The effect of soft palatal resection on the scores of EAT-10 was also examined in the same way. The results of ODK and MTP with or without a maxillofacial prosthesis were compared using Wilcoxon signed rank test. Correlations between EAT-10 scores and patient-related continuous variables including age, number of remaining teeth, tongue functions, and oral dryness examined with Spearman correlation coefficients. Statistical significance was set at $P<0.05$. All statistical analyses were performed using JMP ${ }^{\circledR}$ Pro (SAS Institute Inc., Cary, NC, USA) 


\section{Results}

\section{Patient profiles}

A total of 47 maxillectomy patients (23 males and 24 females, median age:71 [IQR: 63-76]) were included in this study. Twenty patients had experienced radiotherapy and 14 patients had undergone partial soft palate resection. The number of remaining teeth was 15 [IQR: 9-21]. All of the patients could use their maxillofacial prostheses without any specific problems such as poor retention and remarkable nasal leakage.

\section{Effect of radiotherapy and soft palate resection on the scores of EAT-10}

The median value of EAT-10 scores in all patients was 3 [IQR: 0-14]. The distribution of EAT-10 scores in patients with or without the history of radiotherapy are shown in Fig. 1. The scores in patients who had experienced radiotherapy were significantly worse than patients who had not $(P<0.05)$, resulting in the rejection of our null hypothesis. The effect of soft palate resection on EAT-10 scores was also evaluated and our analysis did not demonstrate a significant difference in EAT-10 scores when comparing patients with or without soft palate resection (Fig.2).

\section{Effects of maxillofacial prostheses on tongue functions}

The median values of ODK and MTP in all patients in this study was 3.8 [IQR:2.8-5.4] and 23.3 [IQR:17.027.4], respectively. Both tongue functions, ODK and MTP, were also measured with or without their maxillofacial prostheses. Both ODK and MTP scores were significantly improved by wearing their maxillofacial prostheses ( $P<0.0001$, Fig. 3 and 4, respectively).

\section{Effects of radiotherapy on oral dryness}

The median values of oral dryness in all patients was 28.2 [IQR:26.6-29.4]. The effect of radiotherapy on oral dryness was evaluated with an oral moisture checker. Our statistical analysis revealed no significant differences in oral dryness between the patients with and without radiotherapy (Fig. 5).

\section{Correlations between EAT-10 scores and continuous variables}

Correlations of EAT-10 scores with continuous variables were analyzed by Spearman's correlation coefficient. Our analyses demonstrated that there was a significant correlation between EAT-10 score and $\operatorname{MTP}(\rho=-0.30, P=0.04)$. This means that the null hypothesis in this study was rejected including the comparative result of EAT-10 scores between the patients with and without radiotherapy. The detailed results of the analyses are shown in Table 1.

\section{Discussion}


Swallowing procedure is known to be a complex activity and be conducted by several factors. In maxillectomy patients, poor swallowing function has been supposed to be caused by their specific conditions such as maxillary defects including soft palate and other cancer therapy-related factors such as radiotherapy $[1,4,14,16]$. In addition, it has been reported that tongue functions play a critical role in swallowing function in maxillectomy patients [23-26]. However, the analyses that focused on the association between swallowing function and tongue functions in maxillectomey patients are still lacking. This study was conducted to examine the effects of maxillectomy patients-specific factors including radiotherapy, and tongue functions on swallowing function using EAT-10 scores.

Our study showed that swallowing function is relatively poor in maxillectomy patients according to the reference value in the previous studies (poor swallowing function: EAT-10 score $=3$ or higher) $[27,28]$. The present study also found that swallowing function was significantly impaired by the history of radiotherapy, meaning that the radiotherapy does not guarantee normal swallowing function as the previous studies demonstrated $[1,2,4,14,16]$ Radiotherapy is one of well-known causes of xerostomia identically to age and some medications [30]. Saliva plays an important role in the preparing the food for swallowing by moistening, lubricating and facilitating bolus formation in addition to food bolus flow. However, the present study demonstrated that we found no significant difference between oral dryness with and without the radiotherapy. We reason that the patients in the present study were maxilletomy patients and targeted radiation for maxillary cancer might reduce the damage and hypofunction of major salivary glands. In our institutional hospital, stereotactic radiotherapy or intensity modulated radiation therapy is often adopted for head and neck, or oral cancers to decrease the risk of surrounding tissue damage [31,32]. As a result, the median values of oral dryness in this study might be 28.0 in the patients without the radiotherapy and 28.4 in the patients with the radiotherapy (the threshold value (27.0) defined by Minakuchi et al. [28], which was approved as threshold value by Ministry of Health, Labour and Welfare in Japan, and Japanese Association for Dental Science). These findings imply that poor swallowing function in patients with the history of radiotherapy is attributed to radiation-induced injury in neuromuscular system [14], although some detailed analyses will be required. On the other hand, there was no difference between patients with and without partial soft palate resection. Soft palate plays an important role in swallowing and it is very difficult to replace the soft palate with the prosthesis compared to hard palate $[33,34]$. There have been previous studies that showed impaired swallowing function by soft palate resection $[22,35]$. In this study, the distribution of EAT-10 scores in patients without soft palate resection was wide range and several patients without soft palate resection also had radiotherapy, which may be a confounding factor in them. Further studies with more patients are required to circumvent this problem.

Tongue functions were significantly improved with maxillofacial prostheses. A removable dental prosthesis with thicker denture base might be sometimes used to improve tongue functions like a palatal augmentation prosthesis (PAP) [36]. However, it is also important to note that, in maxillectomy patients with a wide range of maxillofacial defects, larger maxillofacial prostheses are inevitably delivered to cover or fill the defects. In many cases, these prostheses tend to be unstable due to larger defects and poor support, resulting in poor functions including tongue functions which was assessed in this 
measurement method. The results of the present study might imply that functionally proper maxillofacial prostheses had been delivered. Improved tongue functions with maxillofacial prostheses might contribute to rehabilitation of swallowing functions as the previous studies showed $[16,17,20]$. Fabrication and delivery of PAP would be determined after the assessment of MTP. However, future studies to investigate the association between defect size and configuration, and quality of maxillofacial prostheses including assessment of their functional contributions will be required.

Several comparative studies have revealed that prosthetic intervention with maxillofacial prostheses or obturators [17, 18], and surgical reconstruction with or without prostheses [13-16] had positive effects on swallowing function. On the other hand, the evidence for an association between swallowing function and several factors in maxillectomy patients including tongue functions with maxillofacial prostheses and cancer treatment-related factors has been lacking. In the present study, a significant correlation of EAT-10 scores with MTP was identified, meaning lower MTP may result in impaired swallowing function in addition to the negative effect of radiotherapy on swallowing function shown in Fig. 1. Based on these findings, the null hypothesis in this study was rejected. Whereas MTP and ODK were enhanced by wearing a prosthesis, only MTP, not ODK, was positively associated with swallowing function. Interestingly, a previous study investigated the association between masticatory performance and both tongue functions, and demonstrated that motor functions of tongue which included both ODK and MTP were significant factor [37]. Furthermore, it has also been reported that ODK was significantly associated with MTP [38]. These findings suggested that both tongue functions play a crucial role in the overall eating process and support our results.

Taken in the light of these findings, following clinical managements will be recommended: 1) If maxillectomy patients showed weak and poor MTP, tongue muscle training and/or PAP might be recommended to improve swallowing function as the previous studies showed [36, 39-41], 2) In addition to tongue muscle training and/or PAP, food management such as the usage of thickener might be considered for maxillectomy patients who had radiotherapy and/or cannot improve tongue functions [16]. Yet, few studies have investigated these impacts on swallowing or nutrition assessment in maxillectomy patients. Future research should focus more specifically on these issues.

Considering the variables in this study and features in maxillectomy patients, we need to discuss the limitation of this study. This study was conducted as a cross-sectional retrospective study and this means that the number of our patients were limited. The defect size and configuration according to some classification might be considered [42, 43]. Furthermore, the duration of maxillofacial prostheses usage was not considered. Although the patients in this study could be classified into several groups according to these classifications, it was unfavorable to analyze statistically due to the limited number of patients. The duration of prostheses usage is also associated with the habituation to prostheses and aging in patients. So far, there have been no longitudinal studies that evaluated oral functions in maxillectomy patients, to our knowledge. The impact of the duration of prostheses usage on oral functions with the consideration of the habituation to prostheses and aging in patients must be important in the future longitudinal study. These factors, including defect size, configuration and prosthesis design in 
maxillectomy patients, could be considered as confounding factors in swallowing function. To investigate the effect of these factors on swallowing function, more sophisticated research with a great number of patients will be required in the future.

\section{Conclusions}

Realizing that there are some limitations of this study, the authors conclude that swallowing function defined by EAT-10 scores is relatively impaired in maxillectomy patients, especially in patients with the history of radiotherapy. Tongue functions can be restored with maxillofacial prostheses. More importantly, swallowing function is significantly influenced by radiotherapy and MTF in the setting of the present study.

\section{Declarations}

Conflict of Interest: All authors declare that we have no conflict of interest.

Ethical approval: The study protocol was approved by our institutional ethics committee (2019-144). All the procedures being performed were part of the routine treatments and assessments. The investigation in the present study was carried out in compliance with Helsinki declaration and the Strengthening the Reporting of Observational Studies in Epidemiology (STROBE) guidelines.

Funding: The authors received no specific funding for this work.

Informed consent (Consent to participate, Consent for publication): This is a retrospective cross sectional study and our ethics committee allowed us to conduct this study without informed consents from individual patients included in this study. However, we gave public notice of this study.

Availability of data and material: All data could be extracted from our medical chart following ethical approval and our institutional guideline. The measurement materials were described in the text and we don't have any declarations to be described.

\section{Authors' contributions:}

Yoichiro Ogino, DDS, PhD: Project administration, Conceptualization, Methodology, Formal analysis and investgation, Writing - original draft preparation

Natsue Fujikawa, DDS: Formal analysis and investgation

Sayuri Koga, DDS, PhD: Formal analysis and investgation

Ryoji Moroi, DDS, PhD: Formal analysis and investgation, Writing - review and editing

Kiyoshi Koyano, DDS, PhD: Supervision, Writing - review and editing 


\section{References}

1. Kreeft AM, Krap M, Wismeijer D, Speksnijder CM, Smeele LE, Bosch SD, Muijen MS, Balm AJ. (2012) Oral function after maxillectomy and reconstruction with an obturator. Int J Oral Maxillofac Surg. 41:1387-1392. https://doi:10.1016/j.ijom.2012.07.014.

2. Chen C, Ren WH, Huang RZ, Gao L, Hu ZP, Zhang LM, Li SM, Dong K, Qi H, Zhi KQ. (2016) Quality of Life in Patients After Maxillectomy and Placement of Prosthetic Obturator. Int J Prosthodont. 29:363368. https://doi:10.11607/ijp.4608.

3. Said MM, Otomaru T, Aimaijiang Y, Li N, Taniguchi H. (2016) Association Between Masticatory Function and Oral Health-Related Quality of Life in Partial Maxillectomy Patients. Int J Prosthodont. 29:561-564. https://doi:10.11607/ijp.4852.

4. Dos Santos DM, de Caxias FP, Bitencourt SB, Turcio KH, Pesqueira AA, Goiato MC. (2018) Oral rehabilitation of patients after maxillectomy. A systematic review. $\mathrm{Br} \mathrm{J}$ Oral Maxillofac Surg. 56:256266. https://doi:10.1016/j.bjoms.2018.03.001.

5. Koyama S, Sasaki K, Inai T, Watanabe M. (2005) Effects of defect configuration, size, and remaining teeth on masticatory function in post-maxillectomy patients. J Oral Rehabil. 32:635-641. https://doi:10.1111/j.1365-2842.2005.01483.x.

6. Matsuyama M, Tsukiyama Y, Tomioka M, Koyano K. (2006) Clinical assessment of chewing function of obturator prosthesis wearers by objective measurement of masticatory performance and maximum occlusal force. Int J Prosthodont. 19:253-257.

7. Reitemeier B, Unger M, Richter G, Ender B, Range U, Markwardt J. (2012) Clinical test of masticatory efficacy in patients with maxillary/mandibular defects due to tumors. Onkologie. 35:170-174. https://doi:10.1159/000337374.

8. Shibuya Y, Ishida S, Kobayashi M, Hasegawa T, Nibu K, Komori T. (2013) Evaluation of masticatory function after maxillectomy using a colour-changing chewing gum. J Oral Rehabil. 40:191-198. https://doi:10.1111/joor.12023.

9. de Groot RJ, Wetzels JW, Merkx MAW, Rosenberg AJWP, de Haan AFJ, van der Bilt A, Abbink JH, Speksnijder CM. (2019) Masticatory function and related factors after oral oncological treatment: A 5-year prospective study. Head Neck. 41:216-224. https://doi:10.1002/hed.25445.

10. de Groot RJ, Merkx MAW, Hamann MNS, Brand HS, de Haan AFJ, Rosenberg AJWP, Speksnijder CM. (2020) Tongue function and its influence on masticatory performance in patients treated for oral cancer: a five-year prospective study. Support Care Cancer. 28:1491-1501. https://doi:10.1007/s00520-019-04913-y.

11. Jean A. (2001) Brain stem control of swallowing: neuronal network and cellular mechanisms. Physiol Rev. 81:929-969. https://doi:10.1152/physrev.2001.81.2.929.

12. Lang IM. (2009) Brain stem control of the phases of swallowing. Dysphagia. 24:333-348. https://doi:10.1007/s00455-009-9211-6. 
13. Jansma J, Vissink A, Bouma J, Vermey A, Panders AK, Gravenmade EJ. (1992) A survey of prevention and treatment regimens for oral sequelae resulting from head and neck radiotherapy used in Dutch radiotherapy institutes. Int J Radiat Oncol Biol Phys. 24:359-367. https://doi:10.1016/03603016(92)90692-b.

14. King SN, Dunlap NE, Tennant PA, Pitts T. (2016) Pathophysiology of Radiation-Induced Dysphagia in Head and Neck Cancer. Dysphagia. 31:339-351. https://doi:10.1007/s00455-016-9710-1.

15. Abdulkareem EH, Aftan KT. (2018) Surgical Treatment of Maxillary Antrum Neoplasms. J Craniofac Surg. 29:e641-e645. https://doi: 10.1097/SCS.0000000000004631.

16. Sezgin B, Durusoy D, Demirci MS, Ozturk K, Kaya I, Eyigor S, Gode S. (2018) The effect of "xanthan gum-based fluid thickener" on hydration, swallowing functions and nutritional status in total maxillectomy patients. Eur Arch Otorhinolaryngol. 275:2997-3005. https://doi:10.1007/s00405-0185167-1.

17. Matsuyama M, Tsukiyama Y, Koyano K. (2005) Objective clinical assessment of change in swallowing ability of maxillectomy patients when wearing obturator prostheses. Int $\mathrm{J}$ Prosthodont. 18:475-479.

18. Vero N, Mishra N, Singh BP, Singh K, Jurel SK, Kumar V. (2015) Assessment of swallowing and masticatory performance in obturator wearers: a clinical study. J Adv Prosthodont. 7:8-14. https://doi:10.4047/jap.2015.7.1.8.

19. Murphy J, Isaiah A, Wolf JS, Lubek JE. (2015) Quality of life factors and survival after total or extended maxillectomy for sinonasal malignancies. J Oral Maxillofac Surg. 73:759-763. https://doi:10.1016/j.joms.2014.11.002.

20. Said MM, Otomaru T, Yeerken Y, Taniguchi H. (2017) Masticatory function and oral health-related quality of life in patients after partial maxillectomies with closed or open defects. J Prosthet Dent. 118:108-112. https://doi: 10.1016/j.prosdent.2016.11.003.

21. Sreeraj R, Krishnan V, V M, Thankappan K. (2017) Comparison of masticatory and swallowing functional outcomes in surgically and prosthetically rehabilitated maxillectomy patients. Int $\mathrm{J}$ Prosthodont. 30:573-576. https://doi:10.11607/ijp.4231.

22. Kamiyanagi A, Sumita Y, Ino S, Chikai M, Nakane A, Tohara H, Minakuchi S, Seki Y, Endo H, Taniguchi H. (2018) Evaluation of swallowing ability using swallowing sounds in maxillectomy patients. J Oral Rehabil. 45:126-131. https://doi:10.1111/joor.12593.

23. Ono T, Hori K, Nokubi T. (2004) Pattern of tongue pressure on hard palate during swallowing. Dysphagia. 19:259-264. https://doi:10.1007/s00455-004-0010-9.

24. Kondoh J, Ono T, Tamine K, Fujiwara S, Minagi Y, Hori K, Maeda Y, KreissI M, Nitschke I. (2015) Effect of complete denture wearing on tongue motor biomechanics during swallowing in edentulous older adults. Geriatr Gerontol Int. 15:565-571. https://doi:10.1111/ggi.12315.

25. Kim HD, Choi JB, Yoo SJ, Chang MY, Lee SW, Park JS. (2017) Tongue-to-palate resistance training improves tongue strength and oropharyngeal swallowing function in subacute stroke survivors with dysphagia. J Oral Rehabil. 44:59-64. https://doi:10.1111/joor.12461. 
26. Hiraoka A, Yoshikawa M, Nakamori M, Hosomi N, Nagasaki T, Mori T, Oda M, Maruyama H, Yoshida M, Izumi Y, Matsumoto M, Tsuga K. (2017) Maximum Tongue Pressure is Associated with Swallowing Dysfunction in ALS Patients. Dysphagia. 32:542-547. https://doi:10.1007/s00455-0179797-z.

27. Belafsky PC, Mouadeb DA, Rees CJ, Pryor JC, Postma GN, Allen J, Leonard RJ. (2008) Validity and reliability of the Eating Assessment Tool (EAT-10). Ann Otol Rhinol Laryngol. 117:919-924. https://doi:10.1177/000348940811701210.

28. Minakuchi S, Tsuga K, Ikebe K, Ueda T, Tamura F, Nagao K, Furuya J, Matsuo K, Yamamoto K, Kanazawa M, Watanabe Y, Hirano H, Kikutani T, Sakurai K. (2018) Oral hypofunction in the older population: Position paper of the Japanese Society of Gerodontology in 2016. Gerodontology. 35:317-324. https://doi:10.1111/ger.12347.

29. Takeuchi N, Sawada N, Ekuni D, Morita M. (2020) Oral diadochokinesis is related to decline in swallowing function among community-dwelling Japanese elderly: a cross-sectional study. Aging Clin Exp Res. (online ahead of print.) https://doi:10.1007/s40520-020-01547-7.

30. Strojan P, Hutcheson KA, Eisbruch A, Beitler JJ, Langendijk JA, Lee AWM, Corry J, Mendenhall WM, Smee R, Rinaldo A, Ferlito A. (2017) Treatment of late sequelae after radiotherapy for head and neck cancer. Cancer Treat Rev. 59:79-92. https://doi:10.1016/j.ctrv.2017.07.003.

31. Mali SB. (2015) Stereotactic radiotherapy for head neck cancer. Oral Oncol. 5:e19-20. https://doi: 10.1016/j.oraloncology.2014.12.010.

32. Quinlan-Davidson SR, Mohamed ASR, Myers JN, Gunn GB, Johnson FM, Skinner H, Beadle BM, Gillenwater AM, Phan J, Frank SJ, William WN, Wong AJ, Lai SY, Fuller CD, Morrison WH, Rosenthal DI, Garden AS. (2017) Outcomes of oral cavity cancer patients treated with surgery followed by postoperative intensity modulated radiation therapy. Oral Oncol. 72:90-97. https://doi:10.1016/j.oraloncology.2017.07.002.

33. Perry A, Anderson K, Lean R, Cotton S. (2002) Elevation of the soft palate in speech and swallowing in normal female participants and females with motor neuron disease: an innovative procedure for measuring palatal elevation. Int J Lang Commun Disord. 37:197-214. https://doi:10.1080/13682820110116857.

34. Britt CJ, Hwang MS, Day AT, Boahene K, Byrne P, Haughey BH, Desai SC. (2019) A Review of and Algorithmic Approach to Soft Palate Reconstruction. JAMA Facial Plast Surg. 21:332-339. https://doi:10.1001/jamafacial.2019.0008.

35. Moya-Plana A, Veyrat M, Honart JF, de Fremicourt K, Alkhashnam H, Sarfati B, Janot F, Leymarie N, Temam S, Kolb F. (2019) Reconstruction of maxillectomy and midfacial defects using latissimus dorsi-scapular free flaps in a comprehensive cancer center. Oral Oncol. 99:104468. https://doi:10.1016/j.oraloncology.2019.104468.

36. Yoshida M, Endo Y, Nishimura R, Masuda S, Amano J, Tsuga K. (2019) Palatal augmentation prosthesis (PAP) can improve swallowing function for the patients in rehabilitation hospital. $J$ Prosthodont Res. 63:199-201. https://doi:10.1016/j.jpor.2018.11.009. 
37. Sagawa K, Furuya H, Ohara Y, Yoshida M, Hirano H, lijima K, Kikutani T. (2019) Tongue function is important for masticatory performance in the healthy elderly: a cross-sectional survey of communitydwelling elderly. J Prosthodont Res. 63:31-34. https://doi:10.1016/j.jpor.2018.03.006.

38. Kobuchi R, Okuno K, Kusunoki T, Inoue T, Takahashi K. (2020) The relationship between sarcopenia and oral sarcopenia in elderly people. J Oral Rehabil. 47:636-642. https://doi: 10.1111/joor.12948.

39. Oh JC. (2015) Effects of Tongue Strength Training and Detraining on Tongue Pressures in Healthy Adults. Dysphagia. 30:315-20. https://doi:10.1007/s00455-015-9601-x.

40. Kim HD, Choi JB, Yoo SJ, Chang MY, Lee SW, Park JS. (2017) Tongue-to-palate resistance training improves tongue strength and oropharyngeal swallowing function in subacute stroke survivors with dysphagia. J Oral Rehabil. 44:59-64. https://doi:10.1111/joor.12461.

41. Namiki C, Hara K, Tohara H, Kobayashi K, Chantaramanee A, Nakagawa K, Saitou T, Yamaguchi K, Yoshimi K, Nakane A, Minakuchi S. (2019) Tongue-pressure resistance training improves tongue and suprahyoid muscle functions simultaneously. Clin Interv Aging. 22:601-608.

https://doi:10.2147/CIA.S194808.

42. Aramany MA. (1978)Basic principles of obturator design for partially edentulous patients. Part I: classification. J Prosthet Dent. 40:554-557. https://doi:10.1016/0022-3913(78)90092-6.

43. Okay DJ, Genden E, Buchbinder D, Urken M. (2001) Prosthodontic guidelines for surgical reconstruction of the maxilla: a classification system of defects. J Prosthet Dent. 86:352-363. https://doi:10.1067/mpr.2001.119524.

\section{Tables}

Table 1 Spearman correlation values between EAT-10 scores and continuous variables

\begin{tabular}{|lll|}
\hline Continuous variables & $\rho$ & P-value \\
Age & 0.21 & 0.15 \\
Number of remaining teeth & -0.01 & 0.92 \\
ODK (/ta/) (times) & -0.27 & 0.07 \\
MTP (KPa) & -0.30 & $0.04^{*}$ \\
Oral dryness & & \\
\hline
\end{tabular}

$\rho=$ Spearman's correlation coefficient, ${ }^{*} \mathrm{P}<0.05$, statistically significant 
Figures

Fig. 1

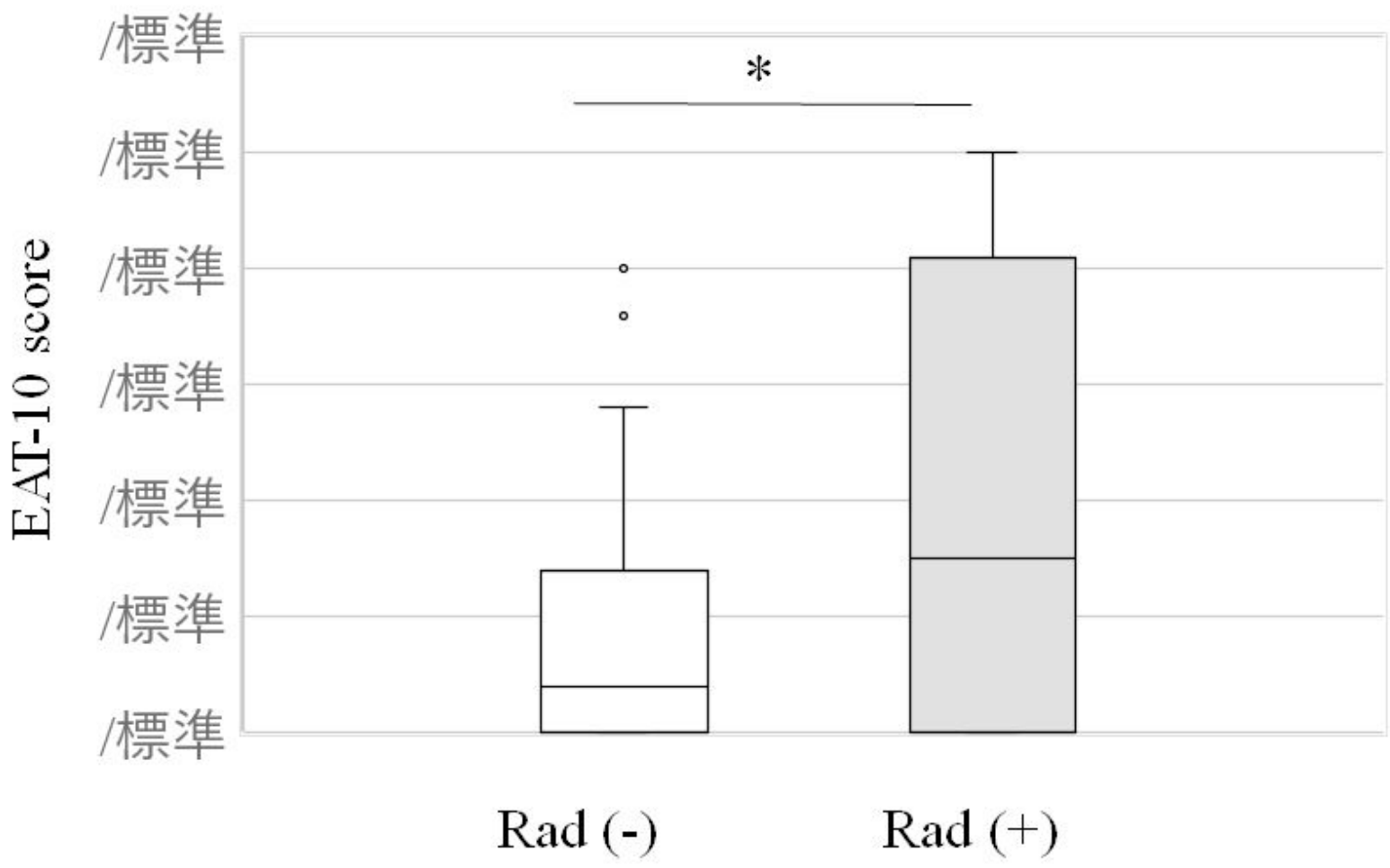

\section{Figure 1}

Comparative analysis of EAT-10 score between the subjects without and with the history of radiotherapy $(\operatorname{Rad}(-)$ and $(+)$ : without and with the history of radiotherapy, respectively). * Wilcoxon rank sum test, $\mathrm{P}<0.05$. 
Fig. 2

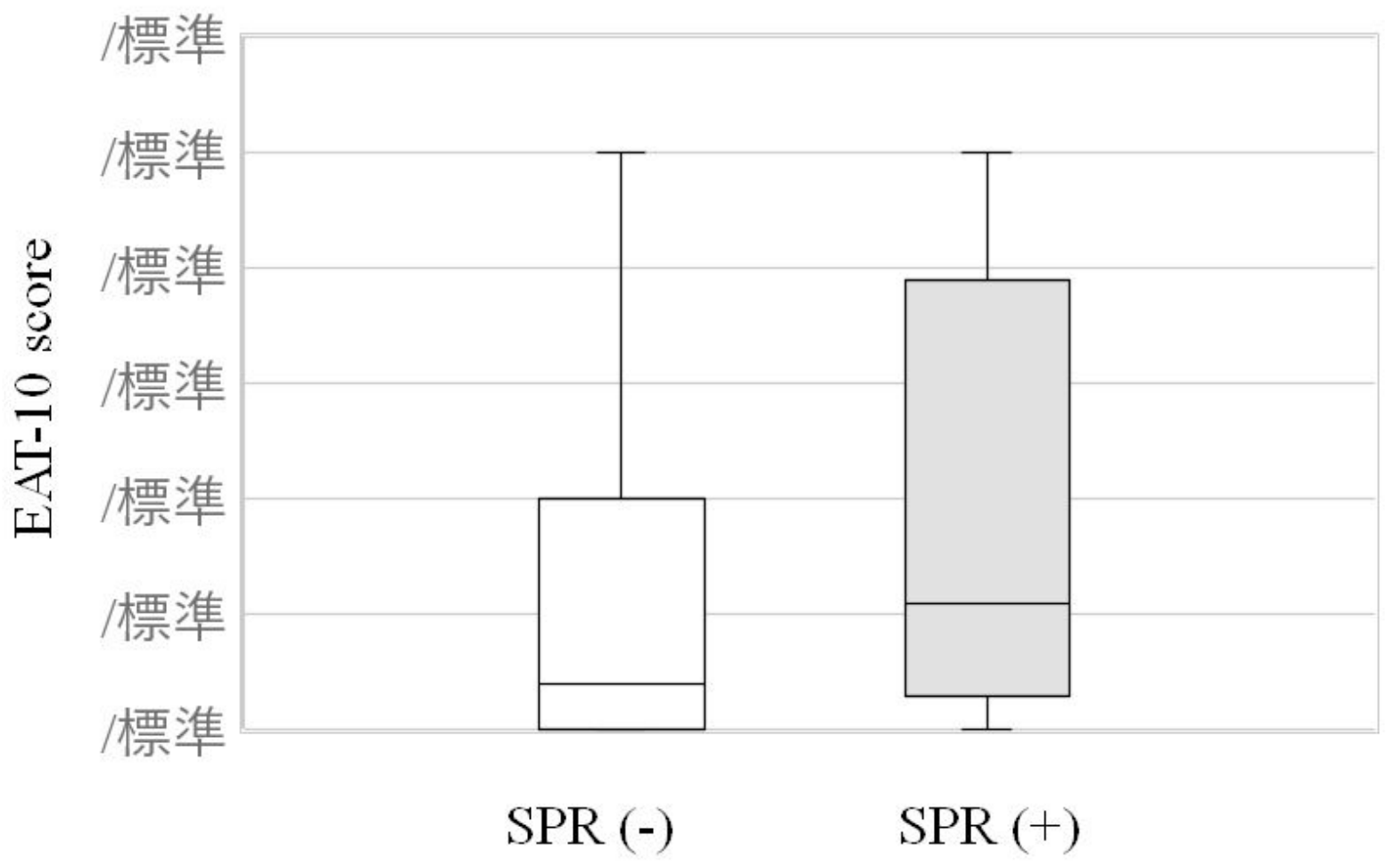

Figure 2

Comparative analysis of EAT-10 score between the subjects without and with soft palate partial resection (SPR (-) and (+): without and with soft palate partial resection, respectively). Wilcoxon rank sum test, no significant difference.

Fig. 3

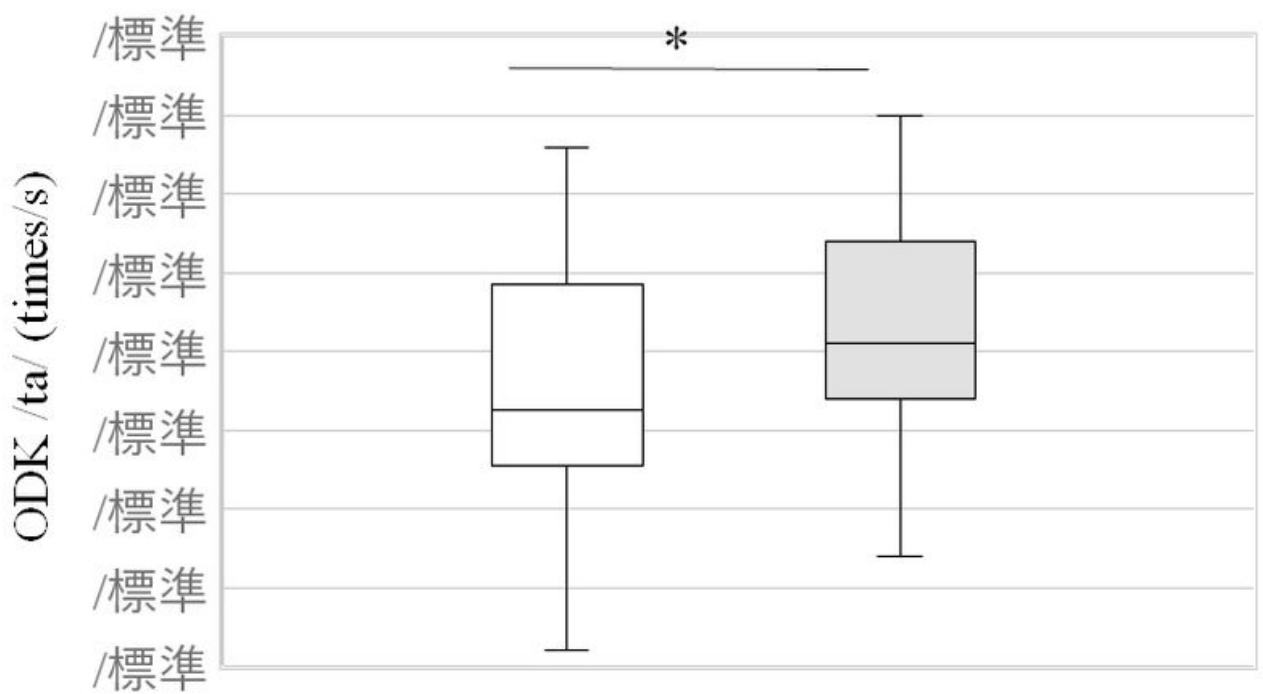

Prosth (-) Prosth (+)

\section{Figure 3}


Comparative analysis of oral diadochokinesis (ODK, /ta/) between the subjects without and with maxillofacial prostheses (Prosth (-) and (+): without and with maxillofacial prostheses, respectively). *Wilcoxon signed rank test, $\mathrm{P}<0.05$.

Fig. 4

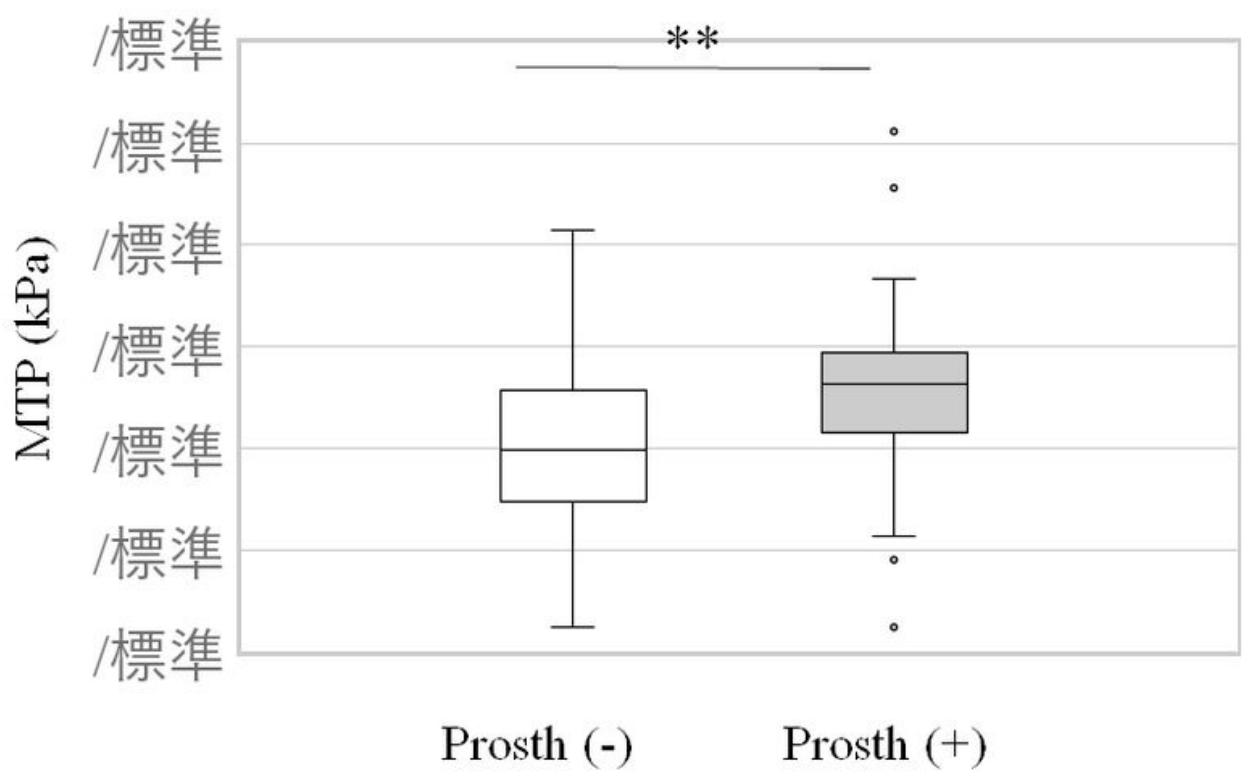

Figure 4

Comparative analysis of maximum tongue pressure (MTP) between the subjects without and with maxillofacial prostheses (Prosth (-) and (+): without and with maxillofacial prostheses, respectively). **Wilcoxon signed rank test, ${ }^{*} \mathrm{P}<0.01$.

Fig. 5

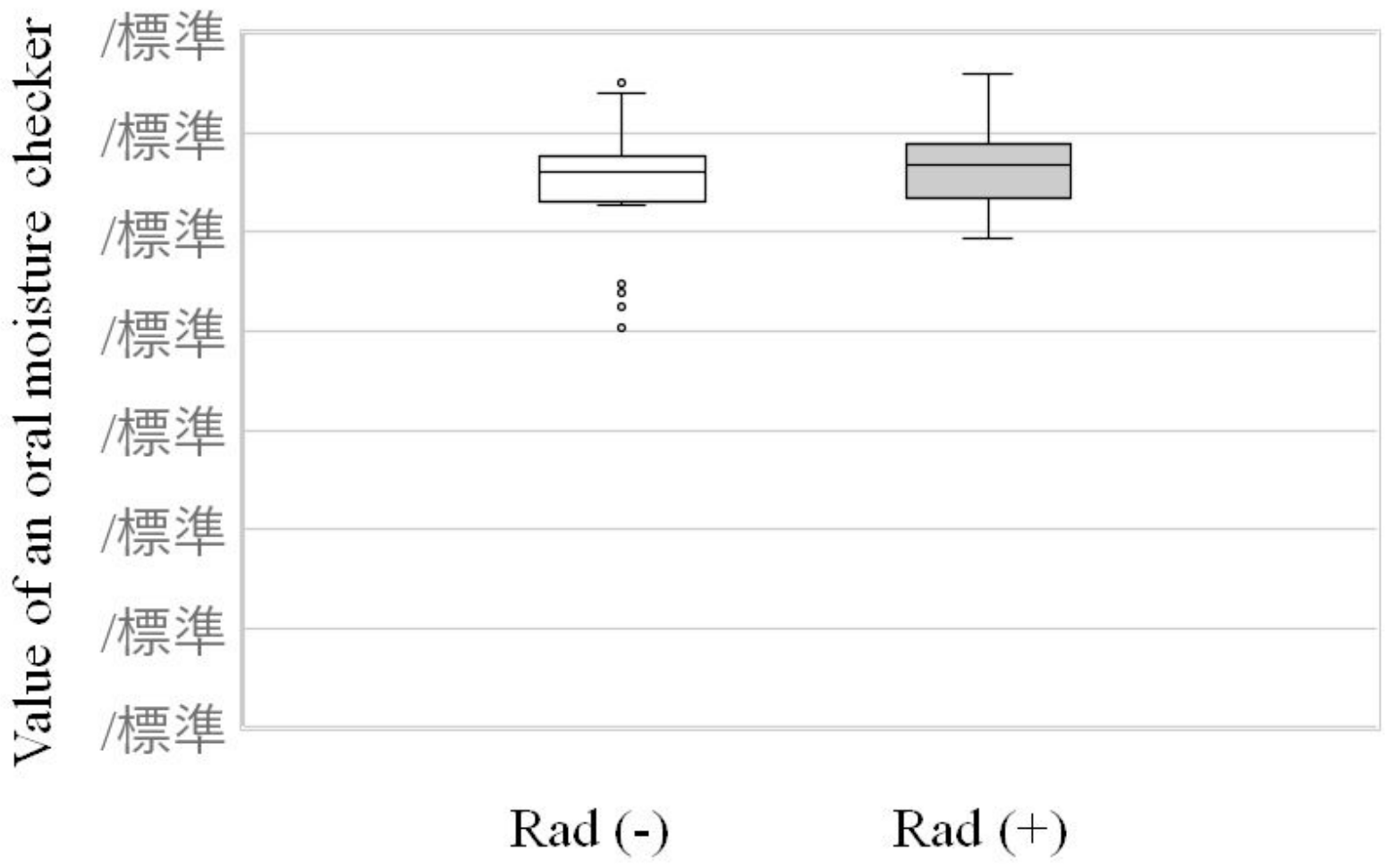




\section{Figure 5}

Comparative analysis of oral dryness between the subjects without and with the history of radiotherapy $(\operatorname{Rad}(-)$ and $(+)$ : without and with the history of radiotherapy, respectively). Wilcoxon rank sum test, no significant difference. 